THE SPACE OF BOREDOM 
This page intentionally left blank 


\title{
THE SPACE OF BOREDOM
}

\author{
HOMELESSNESS IN
}

THE SLOWING GLOBAL ORDER

Bruce O'Neill

Duke University Press · Durham and London · 2017 
(C) 2017 Duke University Press

All rights reserved

Printed in the United States of America on acid-free paper $\infty$

Typeset in Minion Pro by Graphic Composition, Inc., Bogart, Georgia

Library of Congress Cataloging-in-Publication Data

Names: O’Neill, Bruce, [date] author.

Title: The space of boredom : homelessness in the slowing global order / Bruce O'Neill.

Description: Durham : Duke University Press, 2017. | Includes bibliographical references and index.

Identifiers: LCCN 2016040911 (print)

LCCN 2016041958 (ebook)

ISBN 9780822363149 (hardcover : alk. paper)

ISBN 9780822363286 (pbk. : alk. paper)

ISBN 9780822373278 (ebook)

Subjects: LCSH: Boredom-Social aspects. | Globalization-Social aspects-

Romania. | Homelessness-Political aspects-Romania. | Romania-Social conditions-1989- | Romania-Economic conditions-1989-

Classification: LCC HN643.5 0542017 (print) | LCC HN643.5 (ebook) |

DDC $306.4-\mathrm{dc} 23$

LC record available at https://lccn.loc.gov/2016040911

Cover art: Photo by Bruce O’Neill. 
To Helen 
This page intentionally left blank 